\title{
Keefektifan Model Quantum Teaching dan Model Somatic Audio Visual \& Intelegency (Savi) Terhadap Hasil Belajar IPA Siswa Kelas IV SD Se-Kecamatan Kutowinangun Tahun Ajaran 2018/2019
}

\author{
Kurnia Wardani Putri ${ }^{1}$, Kartika Chrysti Suryandari ${ }^{2}$, Drs. Joharman, M.Pd. ${ }^{3}$ \\ 1,2,3 Universitas Sebelas Maret \\ kurniawardaniputri@student.uns.ac.id
}

Article History

accepted 01/02/2020

approved 01/03/2020

published 01/04/2020

\begin{abstract}
Education in the 21st century requires innovative learning, one of which is in the form of Quantum Teaching and Somatic Audio Visual and Intelligence (SAVI) learning models. The purpose of this study is to analyze the effectiveness of the Quantum Teaching learning model and the Somatic Audio Visual and Intelligence (SAVI) learning model on the learning outcomes of Natural Science students in grade IV elementary school. This research is an experimental research with a quantitative approach. The population of this research is all grade IV elementary school students in Kutowinangun District in the academic year 2018/2019. The research sample was selected using the cluster random sampling method. Data collection techniques using tests and observations. The results of this study indicate that the effect sizes of the Quantum Teaching and SAVI classes in this study are 0.533 and 0.396 respectively, which are medium effect size values. Based on these results it can be concluded that the Quantum Teaching model is more effective than the SAVI model in improving science learning outcomes of Grade IV students of Primary Schools in Kutowinangun District in the academic year 2018/2019. The Quantum Teaching learning model is more suitable for learning related to the natural environment than the SAVI learning model.
\end{abstract}

Keywords: Quantum Teaching, Somatic Audio Visual and Intelegency (SAVI), Learning Outcomes

\begin{abstract}
Abstrak
Pendidikan pada abad-21 diperlukan pembelajaran yang inovatif, salah satunya dalam bentuk model pembelajaran Quantum Teaching dan Somatic Audio Visual and Intelegency (SAVI). Tujuan penelitian ini menganalisis efektifitas model pembelajaran Quantum Teaching dan model pembelajaran Somatic Audio Visual and Intelegency (SAVI) terhadap hasil belajar IPA siswa kelas IV SD. Penelitian ini merupakan penelitian eksperimen dengan pendekatan kuantitatif. Populasi penelitian ini adalah seluruh siswa kelas IV SD se-Kecamatan Kutowinangun tahun ajaran 2018/2019. Sampel penelitian dipilih menggunakan metode cluster random sampling. Teknik pengumpulan data menggunakan tes dan observasi. Hasil penelitian ini menunjukkan bahwa nilai effect size kelas Quantum Teaching dan SAVI pada penelitian ini masing-masing 0,533 dan 0,396 yang merupakan nilai effect size sedang. Berdasarkan hasil penelitian tersebut dapat disimpulkan bahwa model Quantum Teaching lebih efektif dibandingkan model SAVI dalam meningkatkan hasil belajar IPA siswa kelas IV Sekolah Dasar se-Kecamatan Kutowinangun tahun ajaran 2018/2019. Model pembelajaran Quantum Teaching lebih sesuai untuk pembelajaran yang berkaitan dengan lingkungan alam sekitar dibandingkan model pemelajaran SAVI.
\end{abstract}

Kata kunci: Quantum Teaching, Somatic Audio Visual and Intelegency (SAVI), hasil belajar 


\section{PENDAHULUAN}

Pendidikan pada abad ke-21 semakin maju dan tuntutan keterampilan yang harus dikuasai peserta didik juga semakin tinggi, termasuk kemampuan peserta didik dalam penguasaan teknologi dan pendidikan moral peserta didik. Tuntutan yang tinggi diharapkan mampu meningkatkan hasil belajar siswa. USC (Paolini: 2015) berpendapat yang menjelaskan bahwa hasil belajar menggambarkan keterampilan, kemampuan, pengetahuan, atau nilai yang diperoleh siswa setelah menyelesaikan suatu program atau pembelajaran. Taurina (2015) mengemukakan pendapat yang berarti hasil belajar digambarkan sebagai pernyataan tertulis tentang apa yang diharapkan diketahui, dipahami, dan/atau dapat dilakukan peserta didik pada akhir periode pembelajaran. Berdasarkan kedua pendapat di atas, maka dapat disimpulkan bahwa hasil belajar merupakan suatu pernyataan tertulis tentang keterampilan, kemampuan, pengetahuan, atau nilai yang diperoleh siswa pada akhir periode pembelajaran. Salah satu hasil belajar siswa sekolah dasar yang perlu diperhatikan yatu hasil belajar IPA.

Mata pelajaran IPA merupakan mata pelajaran yang mempelajari ilmu-ilmu yang ada di lingkungan sekitar anak. Dengan mempelajari IPA, anak akan mampu memahami lingkungan sekitar yang menjadi daerah tempat tingalnya, sehingga anak mampu beradaptasi dengan baik dengan lingkungan. Purnamasari, Suwarto, dan Hadiyah (2013) mengemukakan bahwa tujuan pembelajaran IPA di sekolah dasar yaitu agar siswa mempunyai pengetahuan, gagasan, dan konsep yang terorganisasi tentang alam sekitar, melalui pengamatan, percobaan, penyimpulan, penyusunan teori, sampai adanya penemuan.

Berdasarkan wawancara dengan beberapa guru kelas IV SDN di Kecamatan Kutowinangun diperoleh fakta bahwa sebagian besar siswa kelas IV masih kurang mampu untuk memahami mata pelajaran IPA. Hal ini terlihat dari hasil penilaian tengah semester 1 yang sebagian siswanya belum mencapai KKM. Guru belum menerapkan model pembelajaran yang variatif dan kreatif dikarenakan guru terfokus untuk menyelesaikan penyampaian materi dalam satu pembelajaran setiap harinya. Hal ini menyebabkan siswa yang memang memiliki kemampuan rendah menjadi kurang dapat mengimbangi alur pembelajaran dan berakibat pada kurangnya pencapaian kompetensi pembelajaran pada mata pelajaran IPA. Selain itu, sebagian besar SDN yang ada di Kecamatan Kutowinangun merupakan SDN yang terletak di pedesaan sehingga fasilitas sarana dan prasarananya masih kurang memadai dibandingkan dengan SDN yang ada di daerah perkotaan. Sarana dan pasarana ini berpengaruh terhadap ketercapaian kompetensi siswa karena dengan adanya sarana dan prasarana yang baik maka siswa akan mampu menyerap pembelajaran dengan lebih baik.

Untuk mengahadapi kendala-kendala dalam pembelajaran IPA, guru perlu mempersiapkan perangkat pembelajaran yang tepat agar dapat mencapai tujuan pembelajaran IPA. Salah satu bagian dari perangkat pembelajaran yang perlu diperhatikan yaitu model pembelajaran. Untuk pembelajaran IPA, model pembelajaran sebaiknya menggunakan model pembelajaran yang menyenangkan dan dapat melibatkan siswa secara aktif dalam pembelajaran. Model pembelajaran yang sesuai untuk menciptakan pembelajaran IPA yang menyenangkan sehingga dapat meningkatkan hasil belajar siswa adalah model pembelajaran Quantum Teaching dan model pembelajaran Somatic Audio Visual and Intelegency (SAVI).

DePorter, Reardon, \& Singer-Nourie (2011: 34) megemukakan bahwa Quantum Teaching adalah model pembelajaran yang merupakan penggubahan berbagai macam interaksi di dalam dan di sekitar momen belajar agar pembelajaraan menjadi efektif dengan menyingkirkan hambatan belajar dan menciptakan proses belajar yang mudah dengan menggunakan musik dan bahan pengajaran yang sesuai. Model pembelajaran Quantum Teaching memberikan ide-ide baru tentang cara menciptakan lingkungan 
yang menyenangkan dan baik untuk pelajar dan mendukung proses pembelajaran (Yaseer, Sukestiyarno, \& Masrukan: 2014). Deporter (dalam Trisnawati, Sari, \& Utami: 2019) juga mengungkapkan bahwa melalui model Quantum Teaching, siswa akan diajak belajar secara lebih nyaman dan menyenangkan, sehingga siswa akan lebih leluasa menemukan berbagai pengalaman baru dalam pendidikan. Menurut Wijayanti (2016) karakteristik dalam model pembelajaran Quantum Teaching yaitu penataan lingkungan belajar yang nyaman dan menyenangkan Karakteristik model pembelajaran Quantum Teaching akan sangat relevan dengan mata pelajaran yang bersifat proses mencari tahu berdasarkan fakta yang ada di lingkungan sekitar sehingga timbul rasa senang terhadap mata pelajaran itu sendiri. Berdasarkan pendapat ahli di atas, maka dapat disimpulkan bahwa model pembelajaran Quantum Teaching merupakan penggubahan berbagai macam interaksi di dalam dan di sekitar momen belajar untuk menciptakan pembelajaran yang efektif, nyaman, dan menyenangkan dengan menyingkirkan hambatan belajar dan menciptakan proses belajar yang mudah dengan menggunakan musik dan bahan pengajaran yang sesuai.

Menurut Ngalimun (2016) pembelajaran SAVI adalah pembelajaran yang menekankan bahwa belajar haruslah memanfaatkan semua alat indra yang dimiliki siswa. Meier: 2002 (dalam Tyas: 2014) juga berpendapat mengenai pengertian SAVI, yaitu suatu model pembelajaran dengan cara menggabungkan gerakan fisik dengan aktivitas, intelektual, dan penggunaan semua alat indra. Dari kedua pendapat tersebut, dapat disimpulkan bahwa SAVI merupakaan model pembelajaran yang memanfaatkan semua alat indra siswa dan dilakukan dengan cara meggabungkan gerakan fisik dengan aktivitas, intelektual, dan penggunaan semua alat indra.

Berdasarkan uraian di atas maka dapat dirumuskan masalah, yaitu bagaimanakah efektifitas model pembelajaran Quantum Teaching dan model pembelajaran Somatic Audio Visual and Intelegency (SAVI) terhadap hasil belajar IPA siswa kelas IV SD se-Kecamatan Kutowinangun tahun ajaran 2018/2019? Tujuan penelitian ini adalah untuk menganalisis efektifitas model pembelajaran Quantum Teaching dan model pembelajaran Somatic Audio Visual and Intelegency (SAVI) terhadap hasil belajar IPA siswa kelas IV SD se-Kecamatan Kutowinangun tahun ajaran 2018/2019.

\section{METODE PENELITIAN}

Penelitian ini merupakan penelitian kuantitatif dengan jenis eksperimen semu (quasi eksperimen) yang merupakan pengembangan dari true experimental design (Sugiyono, 2016). Populasi penelitian ini adalah seluruh siswa kelas IV SD seKecamatan Kutowinangun tahun ajaran 2018/2019. Sampel penelitian dipilih menggunakan metode cluster random sampling berjumlah 60 siswa dari SDN 2 Lumbu, SDN 2 Triwarno, dan SDN 2 Karangsari untuk kelas Quantum Teaching dan 77 siswa dari SDN 2 Mekarsari, SDN Korowelang, dan SDN Ungaran untuk kelas SAVI. Penelitian dilaksanakan bulan Mei 2019 di enam sekolah yang berada di Kecamatan Kutowinangun, Kabupaten Kebumen, Provinsi Jawa Tengah. Teknik pengumpulan data pada penelitian ini yaitu tes dan observasi. Tes digunakan untuk mengumpulkan data hasil belajar kognitif. Observasi digunakan untuk mengumpulkan data hasil belajar afektif dan psikomotor. Penelitian diawali dengan melakukan pretest dan diakhiri dengan posttest. Pembelajaran dilakukan sebanyak tiga kali pertemuan dan selama pembelajaran berlangsung dilakukan observasi untuk mendapatkan nilai afektif dan psikomotor. Sebelum dilakukan penelitian dilakukan uji coba terlebih dahulu terhadap instrument penelitian agar teruji validitas, reliabilitas, dan daya pembedanya. Kemudian hasil penelitian akan dianalisis dengan uji paired samples $t$ test dan uji effect size yang dilakukan dengan bantuan aplikasi PASW Statistics 18. 
HASIL DAN PEMBAHASAN

Pada penelitian ini diperoleh data nilai kognitif, afektif, dan psikomotor. Untuk data nilai kognitif terdiri dari nilai pretest dan posttest yang dapat dilihat pada grafik berikut ini.

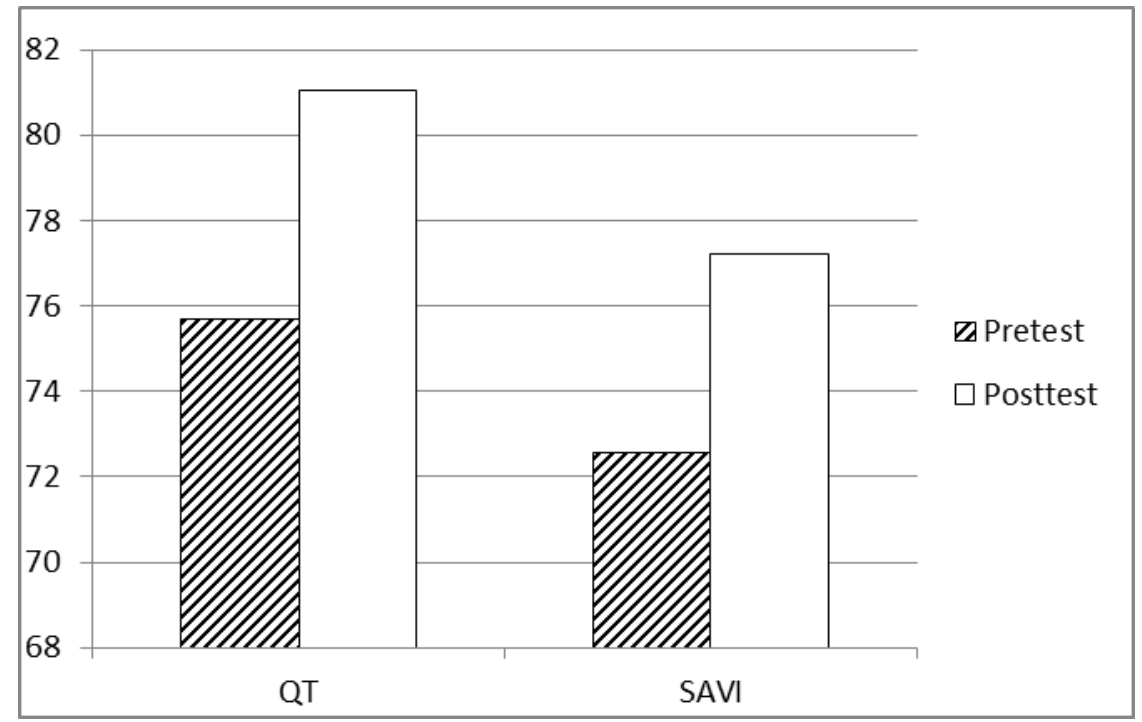

Gambar 1 Rekapitulasi Hasil Belajar Kognitif IPA

Berdasarkan grafik di atas dapat diketahui bahwa terdapat kenaikan nilai dari pretest ke posttest di kedua kelas eksperimen yang menunjukkan bahwa kedua model pembelajaran sama-sama berpengaruh terhadap hasil belajar IPA siswa. Selisih ratarata nilai prestest dan posttest pada kelas Quantum Teaching lebih besar dibandingkan kelas SAVI. ini.

Sedangkan untuk nilai afektif dan psikomotor dapat dilihat pada grafik berikut

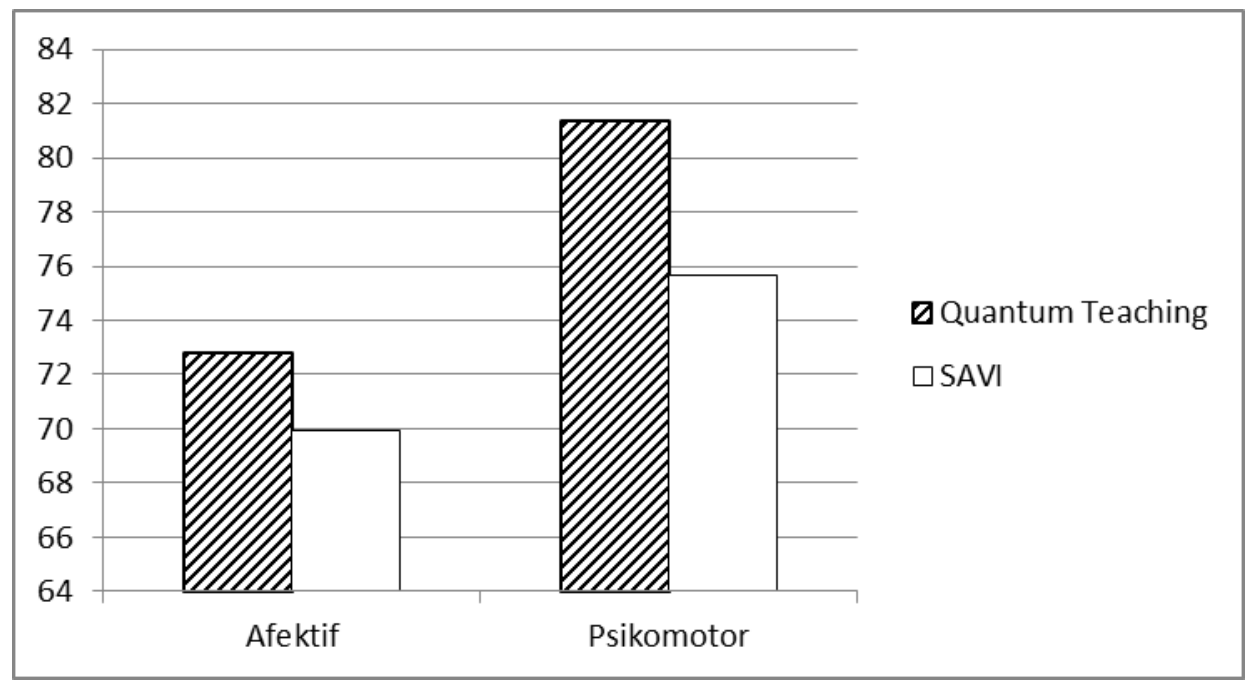

Gambar 2 Rekapitulasi Hasil Belajar Afektif dan Psikomotor IPA

Grafik di atas menunjukkan bahwa nilai afektif dan psikomotor kelas Quantum Teaching lebih tinggi dibandingkan kelas SAVI. Ini berarti model pembelajaran Quantum Teaching lebih berpengaruh dalam meningkatkan hasil belajar IPA siswa.

Analisis data penelitian diawali dengan uji Paired Sample T-Test yang mana diperoleh hasil bahwa pada kelas Quantum Teaching nilai thitung sebesar 6,125 (lebih besar dari tabel yaitu 2,000) dan pada kelas SAVI nilai thitung sebesar 7,201 (lebih besar 
dari $t_{\text {tabel }}$ yaitu 1,991). Hal ini menunjukkan bahwa kedua model dapat meningkatkan hasil belajar kognitif IPA siswa.

Dilanjutkan uji effect size dan diperoleh nilai effect size kelas Quantum Teaching dan kelas SAVI secara berturut-turut adalah 0,533 dan 0,396. Berdasarkan kriteria effect size yang dikemukakan oleh Cohen (Dewi: 2013), kedua kelas eksperimen termasuk dalam ukuran nilai effect size sedang. Ini berarti model pembelajaran Quantum Teaching dan Somatic Audio Visual and Intelegency (SAVI) memiliki efek sedang terhadap hasil belajar kognitif IPA. Namun, nilai effect size pada kelas Quantum Teaching lebih besar dibandingkan nilai effect size pada kelas SAVI. $\mathrm{Hal}$ ini menunjukkan bahwa model pembelajaran Quantum Teaching memiliki pengaruh yang lebih efektif terhadap hasil belajar kognitif IPA siswa dibandingkan model pembelajaran Somatic Audio Visual and Intelegency (SAVI).

Efektiftas model pembelajaran Quantum Teaching lebih besar dibandingkan efektiftas model pembelajaran SAVI dalam meningkatkan hasil belajar IPA siswa kelas IV SD karena model pembelajaran Quantum Teaching unggul dalam langkah-langkah pembelajaran dan asas yang digunakan. Model pembelajaran Quantum Teaching memiliki keunggulan pada langkah-langkah pembelajaran di kelas yang memiliki 6 langkah. Keenam langkah tersebut biasa disebut TANDUR yang terdiri dari tumbuhkan, alami, namai, demonstrasikan, ulangi, dan rayakan (Rumapea, Syahputra, \& Surya: 2017). Dalam penelitian ini juga kelas Quantum Teaching melalui 6 langkah pembelajaran tersebut. Pada langkah tumbuhkan guru mengajak siswa untuk bernyanyi atau melakukan tepuk bersama di awal pembelajaran untuk mendapatkan fokus dan minat siswa terhadap pembelajaran. Pada langkah alami siswa akan melakukan suatu pengamatan atau eksperimen. Langkah namai dilakukan dengan guru memberikan kata kunci untuk pemahaman materi berkaitan dengan pengamatan atau eksperimen yang telah dilakukan oleh siswa. Langkah demonstrasikan dilakukan dengan memberikan kesempatan kepada siswa untuk menunjukkan hasil pembelajaran yang telah diperoleh siswa. Lagkah ulangi dilakukan dengan pengulangan pembahasan materi pokok yang telah dipelajari bersama dan siswa mengerjakan soal latihan. Langkah rayakan dilakukan dengan memberikan penghargaan kepada siswa atas perolehan keterampilan dan pengetahuan baru di kelas dengan memberikan pujian, sticker, atau tepuk salut kepada siswa. Hasil penelitian ini sesuai dengan pendapat dari Wijayanti (2016) yang mengungkapkan bahwa karakteristik model pembelajaran Quantum Teaching akan sangat relevan dengan mata pelajaran yang bersifat proses mencari tahu berdasarkan fakta yang ada di lingkungan sekitar sehingga timbul rasa senang terhadap mata pelajaran itu sendiri.

Model pembelajaran Quantum Teaching memiliki asas utama "Bawalah dunia mereka ke dunia kita, dan antarkan dunia kita ke dunia mereka" (DePorter, Reardon, \& Singer-Nourie, 2011: 35). Diawali dengan memasuki dunia mereka maka akan memberikan izin kepada guru untuk memimpin, membimbing dan memudahkan siswa untuk menerima pembelajaran. Langkah ini dilakukan dengan cara mengaitkan apa yang diajarkan dengan sebuah peristiwa, pikiran, atau perasaan yang diperoleh dari kehidupan rumah, sosial, atletik, musik, seni, rekreasi, atau akademis anak. Setelah kaitan itu terbentuk, guru dapat membawa anak ke dunia guru dan memberikan materi pembelajaran yang hendak dicapai. Pada penelitian ini guru mengaitkan materi pembelajaran dengan kehidupan sehari-hari siswa dan guru juga memperdengarkan musik pengiring pembelajaran selama proses belajar mengajar berlangsung. Musik yang digunakan yaitu musik klasik dengan volume sedang.

Musik klasik menghasilkan gelombang alfa yang menenangkan yang dapat merangsang sistem limbik jaringan neuron otak, mampu memperbaiki konsentrasi ingatan dan persepsi spasial, kemampuan-kemampuan motorik, visual, auditif dan sentuhan makin dioptimalkan melalui stimulasi dengan memperdengarkan musik 
klasik. Ritme, melodi, dan harmoni dari musik klasik dapat memberikan stimulasi untuk meningkatkan kemampuan belajar anak (Rini dalam Gumanti, Supriadi, \& Suherman: 2018).

Hal ini dapat meningkatkan konsentrasi belajar siswa dan pemahaman siswa terhadap materi pembelajaran sehingga model pembelajaran Quantum Teaching efektif untuk meningktkan hasil belajar siswa. Seperti yang diungkapkan oleh DePorter, Reardon, dan Singer-Nourie (2011: 34) bahwa Quantum Teaching adalah model pembelajaran yang merupakan penggubahan berbagai macam interaksi di dalam dan di sekitar momen belajar agar pembelajaraan menjadi efektif dengan menyingkirkan hambatan belajar dan menciptakan proses belajar yang mudah dengan menggunakan musik dan bahan pengajaran yang sesuai. Sejalan dengan, DePorter, Reardon, dan Singer-Nourie Sholikhah (2017) juga mengungkapkan bahwa pembelajaran menggunakan model Quantum Teaching akan lebih mudah dan lebih fokus terhadap materi yang disampaikan dan berusaha memahaminya, sehingga pembelajaran berjalan aktif dan efektif.

\section{SIMPULAN}

Berdasarkan hasil uji effect size pada penelitian ini diperoleh hasil bahwa nilai effect size pada kelas Quantum Teaching dan kelas SAVI secara berturut-turut yaitu 0,533 dan 0,396 yang merupakan nilai efek sedang. Hal ini menunjukkan bahwa kedua model pembelajaran efektif untuk meningkatkan hasil belajar IPA siswa kelas IV SD, namun keefekifan model pembelajaran Quantum Teaching lebih baik dibandingan model pembelajaran SAVI dilihat dari nilai effect size model pembelajaran Quantum Teaching yang lebih besar dibandingkan nilai effect size model pembelajaran SAVI. Hasil penelitian ini memberikan implikasi bhawa model pembelajaran Quantum Teaching lebih sesuai untuk pembelajaran yang berkaitan dengan lingkungan alam sekitar dibandingkan model pemelajaran SAVI.

Berdasarkan hasil penelitian yang telah diperoleh, penulis memberikan saran sebagai berikut: (1) sekolah dan guru perlu mempertimbangkan penggunaan model pembelajaran Quantum Teaching dan SAVI dalam pembelajaran IPA khususnya model pembelajaran Quantum Teaching yang diimbangi dengan penyediaan media penunjang untuk pelaksanaan model pembelajaran tersebut; (2) bagi peneliti lain, penelitian ini dapat dijadikan sebagai sumber referensi dan inspirasi dalam pelaksanaan penelitian yang serupa yaitu mengenai keefektifan penggunaan model pmbelajaran Quantum Teaching dan Somatic Audio Visual and Intelegency (SAVI).

\section{DAFTAR PUSTAKA}

DePorter, B., Reardon, M., \& Singer-Nourie, S. (2011). Quantum Teaching: Mempraktikkan Quantum Learning di Ruang-Ruang Kelas. Terj. Ary Nilandari. Bandung: Kaifa.

Dewi, K. E. (2013). Peningkatan Hasil Belajar IPA Menggunakan Model Cooperative Learning Teknik Marry Go Round pada Siswa Kelas IV B SD Negeri Klegung I. Jurnal IImiah Guru Caraka Olah Pikir Edukatif, 17 (2), 19-28.

Gumanti, A. A. M., Supriadi, N., \& Suherman, S. (2018). Pengaruh Pembelajaran dengan Musik Klasik Terhadap Kemampuan Pemecahan Masalah Matematis Peserta Didik. Prosiding Seminar Nasional Matematika dan Pendidikan Matematika, 1(2), 393-399.

Ngalimun. (2016). Strategi dan Model Pembelajaran. Yogyakarta: Aswaja Pressindo.

Paolini, A. (2015). Enhancing Teaching Effectiveness and Student Learning Outcomes. The Journal of Effective Teaching, 15(1), 20-23.

Purnamasari, L., Suwarto, W. A., \& Hadiyah. (2013). Pengaruh Model SAVI Terhadap Pemahaman Konsep Pesawat Sederhana Ditinjau dari Kreativitas Belajar. Jurnal Mahasiswa PGSD, 1(5). 
Rumapea, G., Syahputra, E., \& Surya, E. (2017). Application of Quantum Teaching Learning Model to Improve Student Learning Outcome. International Journal of Novel Research in Education and Learning, 4(2).

Sholikhah, O. H. (2017, July). Implementation of Quantum Teaching Learning Viewed from Multiple Intelligences in Mathematics Learning. Proceeding International Seminar of Primary Education, 1(2), 1-8.

Sugiyono. (2016). Metode Penelitian Manajemen. Bandung: Alfabeta.

Taurina, Z. (2015). Students' Motivation and Learning Outcomes: Significant Factors in Internal Study Quality Assurance System. International Journal for CrossDisciplinary Subjects in Education (IJCDSE), 5(4), 2625-2630.

Trisnawati, T., Sari, W. R., \& Utami, B. H. S. (2019). The Enhancement of Learning Mathematic's Motivation by Using Application of Quantum Learning Model Teaching. International Journal of Trends in Mathematics Education Research, 2(4), 197-201.

Tyas, E. N. (2014). Peningkatan Keterampilan Proses dan Hasil Belajar Subtema Tugasku Sehari-hari di Rumah Menggunakan Model Pembelajaran SAVI pada Siswa Kelas II SDN 1 Bolo. Scholaria: Jurnal Pendidikan dan Kebudayaan, 4(3), 68-82.

Wijayanti, A. (2016). Pengaruh Quantum Teaching dalam Pembelajaran IPA Terhadap Hasil Belajar Siswa Kelas III SD se-Gugus 2 Hasanudin. BASIC EDUCATION, 5(34), 3-187.

Yaseer, A., Sukestiyarno, \& Masrukan. (2014). Learning Quantum Teaching Model With Atong Approach School Program Of Integrated Valid To Improve Character And Critical Thinking In Probability Material. International Conference on Mathematics, Science, and Education, 5(2), 85-91. 